Document downloaded from:

http://hdl.handle.net/10251/80022

This paper must be cited as:

Desantes Fernández, JM.; Salvador Rubio, FJ.; Carreres Talens, M.; Jaramillo-Císcar, D. (2015). Experimental Characterization of the Thermodynamic Properties of Diesel Fuels Over a Wide Range of Pressures and Temperatures. SAE International Journal of Fuel and Lubricants. 8(1):190-199. doi:10.4271/2015-01-0951.

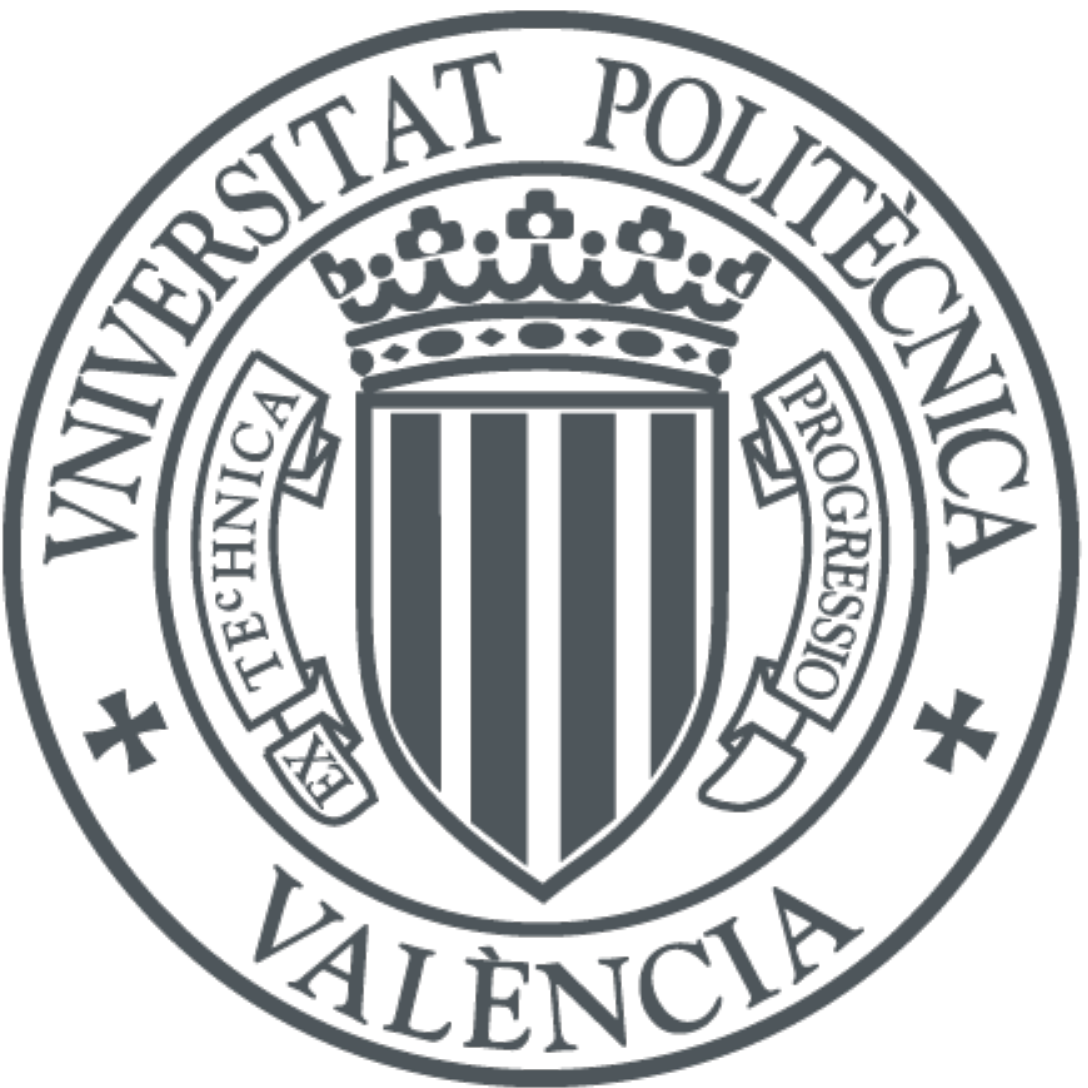

The final publication is available at

http://dx.doi.org/:10.4271/2015-01-0951

Copyright SAE International

Additional Information 


\title{
Experimental Characterization of the Thermodynamic Properties of Diesel Fuels over a Wide Range of Pressures and Temperatures
}

\author{
Author, co-author (Do NOT enter this information. It will be pulled from participant tab in \\ MyTechZone) \\ Affiliation (Do NOT enter this information. It will be pulled from participant tab in MyTechZone)
}

\begin{abstract}
The influence of pressure and temperature on some of the important thermodynamic properties of diesel fuels has been assessed for a set of fuels. The study focuses on the experimental determination of the speed of sound, density and compressibility (via the bulk modulus) of these fuels by means of a method that is thoroughly described in this paper. The setup makes use of a common-rail injection system in order to transmit a pressure wave through a high-pressure line and measure the time it takes for the wave to travel a given distance. Measurements have been performed in a wide range of pressures (from atmospheric pressure up to $200 \mathrm{MPa}$ ) and temperatures (from 303 to $353 \mathrm{~K}$ ), in order to generate a fuel properties database for modelers on the field of injection systems for diesel engines to incorporate to their simulations.
\end{abstract}

\section{Introduction}

The performance of diesel engines is strongly influenced by the thermodynamic properties of fuels for several reasons. Differences from one fuel to another may affect the injector operation, thus affecting the spray evolution and influencing the quality of the airfuel mixture, which in turn affects the combustion phenomenon. This will result in different levels of emissions, noise and performance of the engine [1].

More specifically, the properties that affect the performance of diesel injection systems include but are not limited to speed of sound, density, viscosity and bulk modulus [2, 3, 4, 5].

With regard to the density, several authors have concluded that fuels with lower density result in a smaller mass flow rate for the same injection conditions (namely injection pressure, backpressure and energizing time), leading to lower mass quantities being introduced in the cylinder [6, 7]. In addition, viscosity plays a key role on injector dynamics, affecting the opening and closing stages of the injector and thus leading to different injection rate shape, injection duration and total mass delivered to the cylinder $[8,9]$. In typical common-rail injector systems, the bulk modulus also affects the injection due to its influence on speed of sound, leading to a different propagation of pressure waves along the injector (from the high pressure pump to the injector needle) thus advancing or delaying the needle opening and the start of injection [10]. Furthermore, the speed of sound and bulk modulus are necessary to perform experimental injection rate measurements with the Bosch method, since the technique is based on the transmission of a pressure wave through a tube [11, 12].

The fuel properties stated before present an important dependence on pressure and temperature, as several authors have reported [2, 5, 13, $14,15]$. However, most of the studies report data either for relatively low pressures, or for fluids different than diesel fuels. Due to the high pressures reached in diesel injection systems nowadays (up to 200 $\mathrm{MPa}$ ) and different temperatures depending on the operating conditions (from cold start to hot conditions), an extension on the database is needed for research purposes. On one hand, this will help experimental researchers understand some consequences that the growing injection pressures will have on the engine performance. On the other hand, this database is especially valuable for modelers, since the inclusion of the variation of the fuel properties with temperature and pressure is becoming a standard in 1D and computational fluid dynamics calculations $[16,17,18]$.

The objective of this paper is to present a methodology to experimentally determine some of the most influencing thermodynamic properties of diesel fuels (namely speed of sound, density and bulk modulus) at a wide range of temperatures (from 303 to $353 \mathrm{~K}$ ) and pressures (up to $200 \mathrm{MPa}$ ), representative of commonrail systems. The methodology consists of transmitting a pressure wave along a high-pressure line and measuring the time it takes for the wave to travel a given distance, thus determining the speed of sound for different conditions. The density values will then be theoretically derived from the speed of sound measurements, also leading to the isothermal bulk modulus determination. The installation is calibrated with an alkane (n-dodecane) whose properties are known for a wide range of temperatures and pressures and the measurements are validated with another known alkane (nheptane). Finally, the methodology is tested for a reference diesel fuel and its winter variation, and correlations are given for the dependence on their properties with pressure and temperature.

\section{Theoretical foundation}

The speed of sound (a) in a fluid imposes how fast a pressure wave will be propagated in the medium. A small pressure disturbance

Desantes, J.M., Salvador, F.J., Carreres, M., Jaramillo, D., "Experimental Characterization of the Thermodynamic Properties of Diesel Fuels Over a Wide Range of Pressures and Temperatures", SAE Int. J. Fuels Lubr. 8(1):2015, doi:10.4271/2015-01-0951.

Page 1 of 12 
travelling through a high-pressure one-dimensional pipe of length $L$ covers that distance in a time $t$, since:

$\mathrm{a}=\frac{L}{t}$

With regard to compressibility, the isentropic and isothermal bulk modulus ( $B_{S}$ and $B_{T}$, respectively) are defined as:

$B_{S}=\rho\left(\frac{\partial p}{\partial \rho}\right)_{S}$

$B_{T}=\rho\left(\frac{\partial p}{\partial \rho}\right)_{T}$

where $p$ is the pressure, $T$ the temperature, $S$ the entropy and $\rho$ the density of the fluid. Both definitions of bulk modulus are related to each other as follows:

$\frac{1}{B_{T}}=\frac{1}{B_{S}}+\frac{T \alpha^{2}}{\rho C_{p}}$

where $\alpha$ is the isobaric coefficient of thermal expansion, whereas $C_{p}$ designates the isobaric heat capacity.

As stated by [19], the isentropic bulk modulus and the speed of sound are related to each other through the density:

$\mathrm{a}^{2}=\frac{B_{S}}{\rho}$

Thus, combining Eqs. (2) to (5):

$\left(\frac{\partial \rho}{\partial p}\right)_{T}=\frac{1}{\mathrm{a}^{2}}+\frac{T \alpha^{2}}{C_{p}}$

This equation can be solved for an isothermal line, thus obtaining the relation between density and speed of sound:

$\rho(p, T)=\rho\left(p_{0}, T\right)+\int_{p_{0}}^{p} \frac{d p}{\mathrm{a}^{2}}+T \int_{p_{0}}^{p}\left(\frac{\alpha^{2}}{c_{p}}\right) d p$

The first term of the right side of Eq. (7) corresponds to the density at a reference pressure. For convenience, this will be taken as the atmospheric pressure, since it can then be directly measured with a hydrometer. The other terms are the deviation to take into account the effect of pressure on the density at a given pressure. The second term can be evaluated from the evolution of the speed of sound with pressure for a given isothermal line. Thus, this term can be evaluated from the speed of sound measurements, given that enough pressures are tested for a certain temperature. Finally, the last term is related to the difference between specific heat capacities $\left(C_{p}\right.$ and $\left.C_{v}\right)$ for the fluid. This difference is not significant for liquids [3, 13, 19], which leads to this last term being the smallest contribution to the density. In addition, it is not modified in a substantial way with the pressure, and thus it will be computed assuming that $\alpha$ and $C_{p}$ are constant. With all, it is possible to calculate the density at any pressure and temperature condition, only by measuring the density at atmospheric pressure and performing the speed of sound measurements in the experimental facility described in the following section. The isentropic bulk modulus can then be evaluated by applying Eq. (5).

\section{Experimental}

It has been demonstrated that the measurement of the density at atmospheric pressure and speed of sound at different pressure and temperature conditions make it possible to determine the density and the isentropic bulk modulus at any condition. Thus, the present section deals with the experimental facilities that allow the measurements of speed of sound and density at atmospheric pressure.

\section{Density measurements}

The first step in order to determine the density of a diesel fuel at any condition of temperature and pressure is to establish the variation of the density with respect to the temperature at the atmospheric pressure, as demonstrated by Eq. (7).

Density measurements were then performed with a standard hydrometer, taking into account the considerations stated by the ASTMD1298, including those corresponding to the calibration procedure. With all, the accuracy of the hydrometer was determined to be $\pm 5 \times 10^{-4} \mathrm{~kg} / \mathrm{m}^{3}$. Measurements were taken at different temperatures ranging from 300 to $350 \mathrm{~K}$, in steps of $5 \mathrm{~K}$. Temperature regulation was achieved by means of a thermostatic bath, shown in Figure 1 together with the used setup.

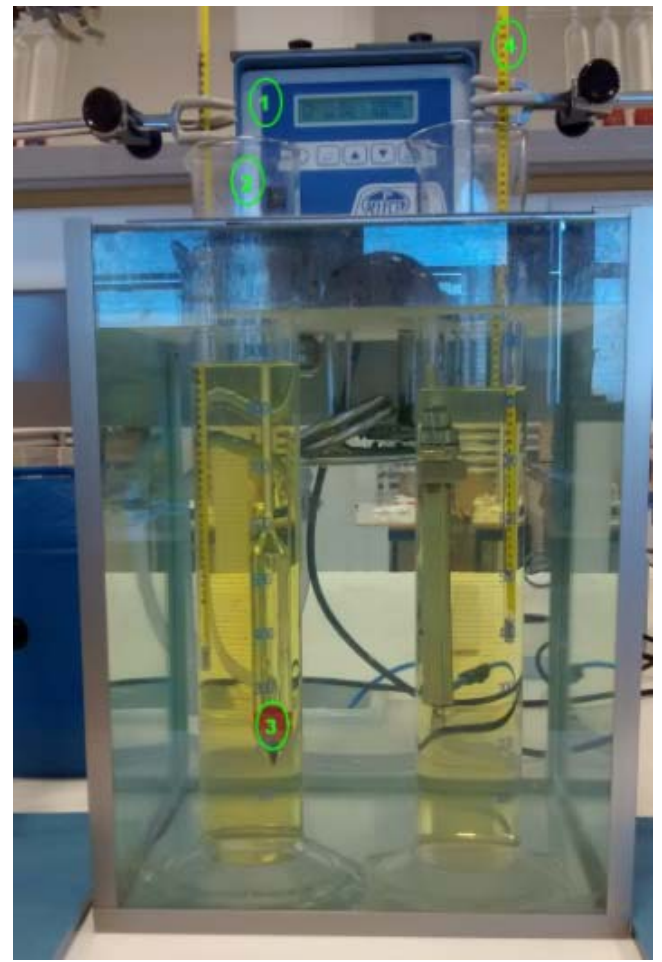

Figure 1. Setup for the measurement of density at atmospheric pressure. The image shows the different equipment used in the facility: 1) temperature regulator; 2) diesel specimen inside a test tube; 3) hydrometer; 4) thermometer.

These tests were also validated by measuring the density by a second procedure, which is based on using a Pycnometer, also following the

Desantes, J.M., Salvador, F.J., Carreres, M., Jaramillo, D., "Experimental Characterization of the Thermodynamic Properties of Diesel Fuels Over a Wide Range of Pressures and Temperatures", SAE Int. J. Fuels Lubr. 8(1):2015, doi:10.4271/2015-01-0951.

Page 2 of 12 
standard method established in the ASTM D1217. The device consists of a volume of $10 \mathrm{ml}$, with an accuracy of $\pm 1.16 \times 10^{-4} \mathrm{ml}$ estimated during its calibration.

\section{Speed of sound measurement facility}

In addition to the determination of the speed of sound itself as an interesting property affecting diesel injection systems, speed of sound measurements are valuable to establish the density of a fuel at high pressures and temperatures. Recall Eq. (7), whose second term at the right side showed the need of determining the speed of sound variation with the pressure for a given temperature.

As it has already been stated, the speed of sound is determined by measuring the time it takes for a pressure perturbation to travel along a certain distance. Several methods have been used in order to determine the speed of sound at pressures higher than the atmospheric, including the ultrasonic cell method [20]. However, in the present work, the authors opted for a setup that allows to couple the facility to the common-rail injection system, with the consequent simplicity to test diesel fuels.

Figure 2 shows an image of the facility and its setup, where it can be seen how the injection system was used. Fuel is extracted from the tank by a high-pressure pump that raises its pressure and delivers it to a rail, where the pressure is controlled. Before reaching the injector, the fuel travels through a long high-pressure pipe, which forms the basis for the measurement, since it is the line through which the measured pressure waves will travel. In order to measure those pressure waves, two piezo-resistive Kistler pressure sensors (able to work under pressures up to $300 \mathrm{MPa}$ ) are located in different points of the high-pressure line, defining the measurement section, as seen in Figure 3.The length of this section needs to be long enough to allow for a clear acquisition, but short enough to minimize signal attenuation. In the end, the length between sensors was established as $4 \mathrm{~m}$. The internal diameter of the pipe needs to be small in order to ensure a one-dimensional transmission of the wave, and was set to 2 $\mathrm{mm}$. After the high-pressure line, the fuel reaches the injector and, in the case of an injection event, is discharged in an Injection Rate Discharge Curve Indicator (IRDCI), where the injected mass flow rate is determined using the Bosch long tube method [11] and registered to check a proper operation of the facility.

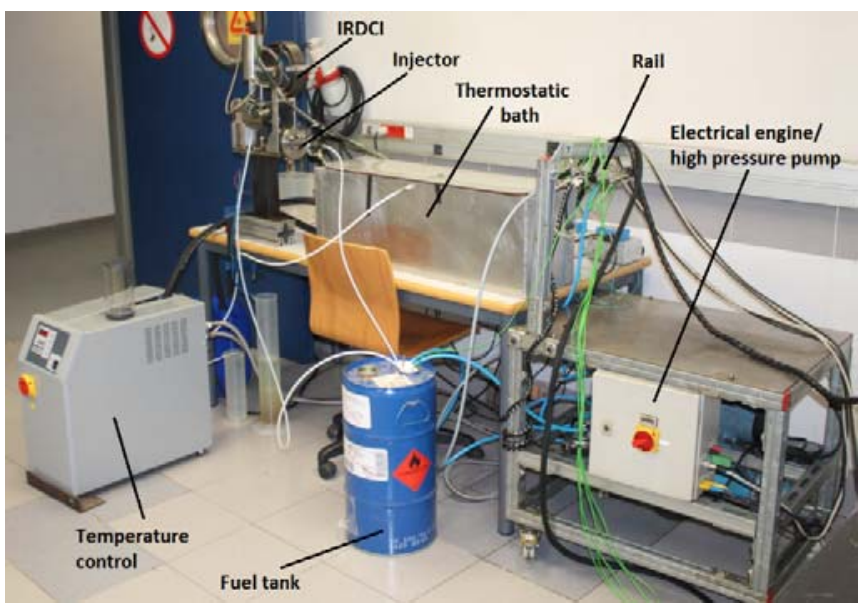

Figure 2. Speed of sound determination experimental setup.

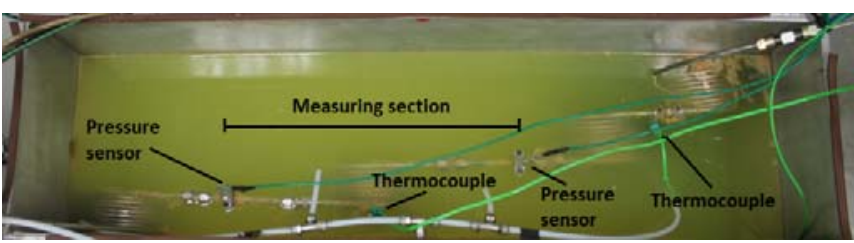

Figure 3. Glycol thermostatic bath of Figure 2, containing the high-pressure lines.

With this setup, a pressure disturbance is produced with an injection event due to the depression generated in the tube by the injector opening, resulting in the fuel being discharged in the IRDCI, as stated in [12]. This pressure disturbance is measured at the two positions of the high-pressure line where the pressure sensors are located. An example of the acquired signals is shown in Figure 4. The injections were carried out at a small frequency $(0.1 \mathrm{~Hz})$ in order to avoid interaction between the waves of successive injections. It is also important to note that a long segment of high-pressure line (about 8 $\mathrm{m}$, which corresponds to twice the length of the measurement section) was left between the measuring section and the injector (recall Figure 4) so that, for a certain injection, the rebound of the pressure wave does not interact with the perturbation being measured, interfering with the signal acquisition. The signal acquisition was performed by means of a Yokogawa DL708 digital oscilloscope and recorded in a personal computer for processing purposes. For each operating point, 25 repetitions were taken. The pressure signals at the two locations were recorded for each of the repetitions and processed in order to obtain the travel time of the pressure wave $(\Delta t)$ between sensors. Finally, an averaged value of $\Delta t$ was accepted as the result, due to the small dispersion between repetitions (quantified as $\pm 0.5 \%$ ).

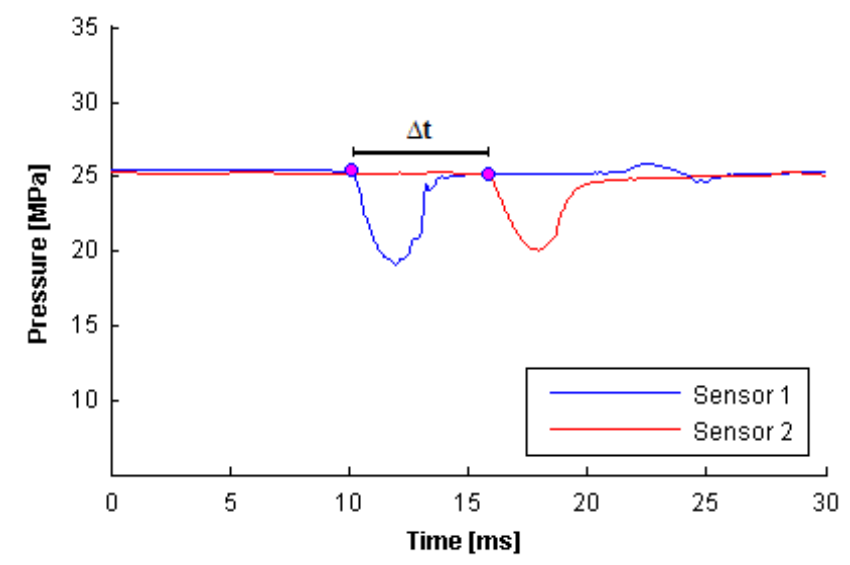

Figure 4. Example of pressure signals captured by the pressure sensors at two different locations of the high-pressure line. The computed $\Delta t$ is taken as the average of 25 repetitions.

In order to control the temperature, the high-pressure lines were immersed in a thermostatic bath filled with glycol, as seen in Figure 3 . Temperature was measured by means of 4 thermocouples at different locations, to ensure temperature uniformity along the bath. The maximum deviations found between locations were $1^{\circ} \mathrm{C}$, confirming good temperature uniformity. The glycol was recirculated

Desantes, J.M., Salvador, F.J., Carreres, M., Jaramillo, D., "Experimental Characterization of the Thermodynamic Properties of Diesel Fuels Over a Wide Range of Pressures and Temperatures", SAE Int. J. Fuels Lubr. 8(1):2015, doi:10.4271/2015-01-0951.

Page 3 of 12 
and its temperature was electronically regulated by a device (see Figure 4) that heated it with an electrical resistance or cooled it down with external water as needed. In addition, temperature was also measured in the fuel tank, rail, injector return line and IRDCI.

Recalling Eq. (1), the proposed methodology implies that the speed of sound is calculated from the $\Delta t$ value measured experimentally and the length $L$ between sensors. However, it is important to note that this length changes with the ambient pressure and temperature:

$\Delta L=L_{0}\left[\alpha_{t}\left(T-T_{0}\right)+\beta_{t}\left(p-p_{0}\right)\right]$

Where $L_{0}$ is the pipe calibrated length at a reference temperature $T_{0}$ and a reference pressure $p_{0}$, whereas $\alpha_{t}$ and $\beta_{t}$ are the coefficients for thermal expansion and compressibility of the pipe material (stainless steel), respectively. Calibration was performed with n-Dodecane, a pure alkane whose speed of sound values are known at different conditions of temperature and pressure. The calibrated length $L_{0}$ was obtained at a reference point of $T_{0}=298 \mathrm{~K}$ and $p_{0}=0.1 \mathrm{MPa}$, by comparing the n-Dodecane measurements with the data theoretically derived from Helmholtz-energy-explicit-type formulations by Bell et al. [21]. These calibration measurements were performed at three different temperatures (303, 323 and $343 \mathrm{~K}$ ) and several pressures up to $100 \mathrm{MPa}$, making it possible to accurately predict $L_{0}$. Thus, for any tested operation condition, the length $L$ used to compute the speed of sound through Eq. (1) is:

$L=L_{0}+\Delta L$

Before actually applying the methodology for fuels of unknown properties, the calibrated value of $L_{0}$ was also validated by performing measurements for $\mathrm{n}$-Heptane and comparing with the CoolProp library [21], as it will be outlined in following sections.

\section{Test matrix}

Measurements were performed for n-Dodecane in order to calibrate the reference length $L_{0}$, n-Heptane to validate the methodology, and a reference fuel and its winter version in order to test the method at high pressures and obtain correlations for speed of sound, density and bulk modulus that can be valuable for modellers. The operating points tested for each fuel are shown in Table 1 . It is important to note that the method has a limitation at low pressures, for which it is not possible to regulate the pressure at the rail. The minimum pressure tested for each fuel is the minimum that allows an acceptable pressure regulation in the rail. Also, n-Dodecane and nHeptane were only tested at pressures up to $100 \mathrm{MPa}$. Even though an increase in pressure leads to higher viscosities, it also leads to an important temperature increase in the fuel pump that leads to a reduction in viscosity. The resulting consequence of these two opposed effects for the n-Dodecane and n-Heptane is a net decrease in viscosity, reaching values way lower than those achieved with diesel fuel, thus strongly affecting the pump lubrication. For this reason, tests at higher pressures were not performed in order to prevent the fuel pump from being damaged.

Table 1. Test matrix for the different fuels tested.

\begin{tabular}{|l|l|l|}
\hline Fuel & Temperatures [K] & Pressures [MPa] \\
\hline
\end{tabular}

\begin{tabular}{|l|l|l|}
\hline n-Dodecane & \multirow{2}{*}{$303,323,343$} & $\begin{array}{l}25,30,40,50,60,70,80, \\
90,100\end{array}$ \\
\cline { 1 - 1 } n-Heptane & $303,313,323,333$, & $\begin{array}{l}50,60,70,80,90,100, \\
110,120,130,140,150, \\
\text { Reference fuel }\end{array}$ \\
\cline { 1 - 1 } Winter fuel & & $160,170,180,190,200$ \\
\hline
\end{tabular}

Details of these fuels at $303 \mathrm{~K}$ and atmospheric pressure are given in Table 2. The values for n-Dodecane and n-Heptane were obtained from [21], whereas the density values shown for the reference and winter fuels have been obtained with the methodology stated in the Experimental section. Viscosity for these fuels at atmospheric pressure was measured with a commercial capillary viscometer, following the standard method established in the ASTM D-445.

Table 2. Fuel density and viscosity reference values at $303 \mathrm{~K}$ and atmospheric pressure.

\begin{tabular}{|l|l|l|}
\hline Fuel & Density $\left[\mathrm{kg} / \mathrm{m}^{3}\right]$ & Viscosity $\left[\mathrm{mm}^{2} / \mathrm{s}\right]$ \\
\hline n-Dodecane & 742.14 & 1.68 \\
\hline n-Heptane & 675.39 & 0.54 \\
\hline Reference fuel & 819.72 & 3.33 \\
\hline Winter fuel & 816.8 & 3.26 \\
\hline
\end{tabular}

\section{Results and discussion}

In this section, the results of applying the presented methodology are shown and discussed. Data will be presented for each of the properties that have been obtained (speed of sound, density and bulk modulus). For each property, results for n-Heptane are presented first, together with a comparison with data from [21], since this constitutes the validation of the methodology. Later on, results for the reference fuel and its winter version are shown, together with polynomial correlations of the properties as a function of temperature and pressure, since this constitutes the preferred format for researchers to apply to their models, due to the possibility of determining the desired property at any condition.

\section{Speed of sound tests}

As it has already been stated, the first step is to check the validity of the methodology once the facility is calibrated with n-Dodecane. To do so, measurements were performed with n-Heptane at the conditions depicted in Table 1. Figures 5 and 6 show the comparison of the n-Heptane experimental results with the data from [21]. In Figure 5, the evolution of the speed of sound with the pressure is shown for the three isothermal curves tested. On the other hand, Figure 6 shows the evolution of the property against the temperature for the isobaric curves. The comparison shows good agreement of the experimental data with the theoretical values, with a $1.24 \%$ maximum deviation, found at the lowest pressures and temperatures. This validates the speed of sound facility and the calibration performed with n-Dodecane. The evolution of the speed of sound with the temperature and pressure is as expected from previous works $[2,5,13,14,20]$ : it increases when the pressure increases, and decreases when the temperature increases. It is also important to state that the dependency with the temperature is nearly linear, whereas the pressure dependency shows a different behavior.

Desantes, J.M., Salvador, F.J., Carreres, M., Jaramillo, D., "Experimental Characterization of the Thermodynamic Properties of Diesel Fuels Over a Wide Range of Pressures and Temperatures", SAE Int. J. Fuels Lubr. 8(1):2015, doi:10.4271/2015-01-0951.

Page 4 of 12 


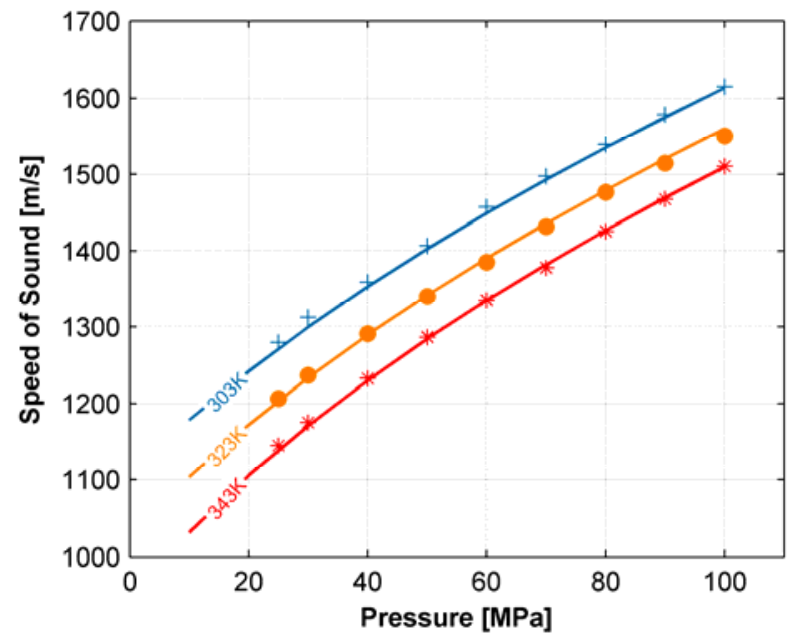

Figure 5. Speed of sound isothermal curves for n-Heptane compared to data from [21]. Experimental results are shown as symbols, whereas data from [21] is represented as continuous lines.

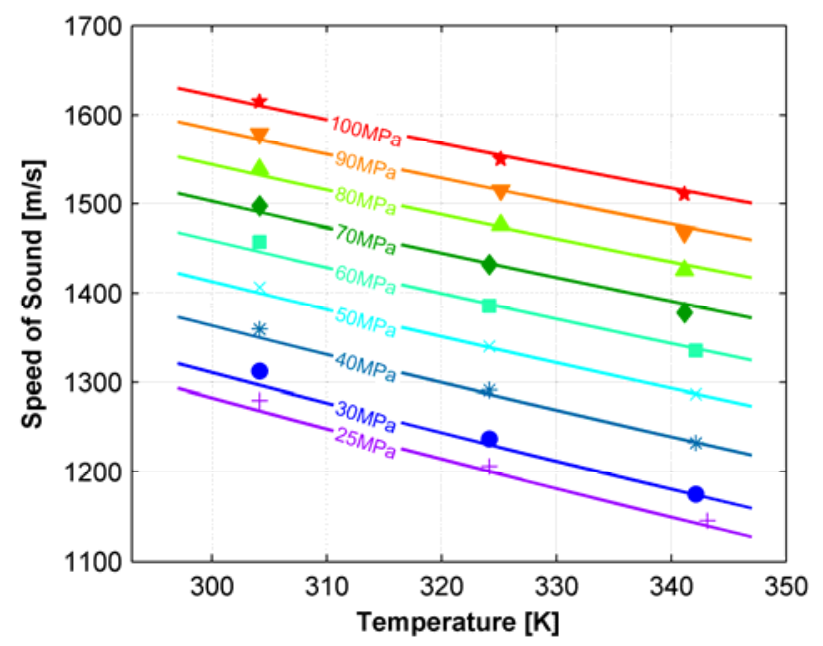

Figure 6. Speed of sound isobaric curves for n-Heptane compared to data from [21]. Experimental results are shown as symbols, whereas data from [21] is represented as continuous lines.

In order to quantify these trends and dispose of suitable data for further reference in the future, the speed of sound has been fitted for each tested fuel to a polynomial expression as a function of temperature and pressure:

$$
\begin{aligned}
\mathrm{a}= & A_{1}+A_{2}\left(T-T_{0}\right)+A_{3}\left(p-p_{0}\right)+A_{4}\left(p-p_{0}\right)^{2}+ \\
& +A_{5}\left(T-T_{0}\right)\left(p-p_{0}\right) \quad(10)
\end{aligned}
$$

As it can be seen, the term corresponding to the dependency with the squared temperature has been omitted, since it has already been stated that this dependency is linear. The coefficients of this expression for each fuel are collected in Table 3, together with the statistical $\mathrm{R}^{2}$ values. The high values of $\mathrm{R}^{2}$ confirm the reliability of this regression and the fact that the speed of sound is virtually linear with respect to the temperature.

Table 3. Eq. (10) correlation coefficients for the different fuels, together with the $\mathrm{R}^{2}$ values.

\begin{tabular}{|l|l|l|l|l|l|l|}
\hline Fuel & $\mathrm{A}_{1}$ & $\mathrm{~A}_{2}$ & $\mathrm{~A}_{3}$ & $\mathrm{~A}_{4}$ & $\mathrm{~A}_{5}$ & $\mathrm{R}^{2}$ \\
\hline n-Heptane & 1152.55 & -3.6693 & 6.6762 & -0.0163 & 0.0071 & 0.9998 \\
\hline Reference & 1363.04 & -3.0832 & 4.2798 & -0.0061 & 0.0072 & 0.9996 \\
\hline Winter & 1350.59 & -3.1485 & 4.4928 & -0.0070 & 0.0074 & 0.9996 \\
\hline
\end{tabular}

Figure 7 represents the experimental results for the reference fuel at the different isothermal lines tested, plotted together with the values obtained through the polynomial expression to which they have been fitted. As the high values of $\mathrm{R}^{2}$ suggested, there is good agreement among the experimental data and the values predicted by the correlation. The fact that the isothermal lines are equally spaced highlights again the linear dependency of the speed of sound with respect to the temperature.

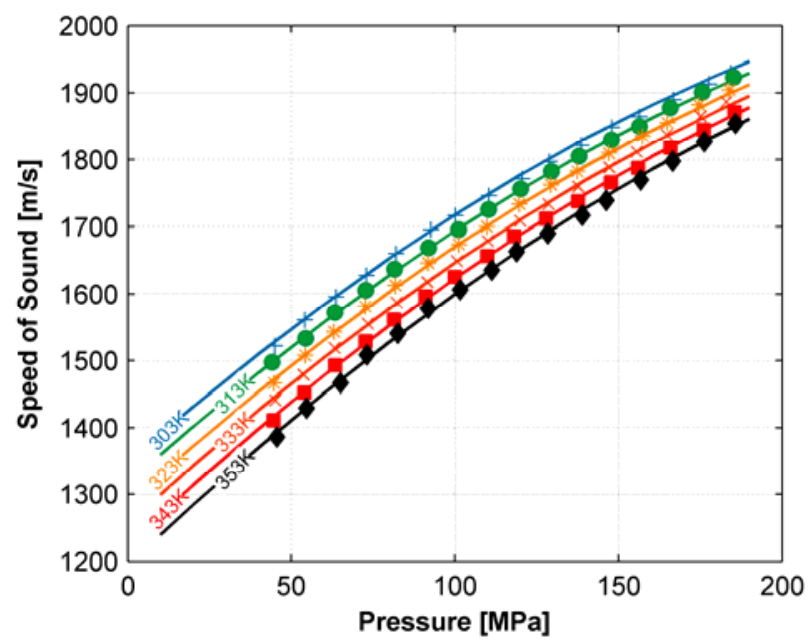

Figure 7. Speed of sound isothermal curves for the reference fuel. Experimental results are shown as symbols, whereas the values corresponding to the regression from Eq.(10) and Table 2 are represented as continuous lines.

Finally, Figures 8 and 9 show a comparison among the reference and the winter fuels, considering only the values predicted by the respective correlations. It can be seen that both fuels present almost the same speed of sound for most of the conditions of pressure and temperature relevant for diesel injection engine operation. Slight differences are only observed at low pressures. This result is interesting, since the industry seeks for winter fuels with the same properties as the standard fuels but with the ability of working at low

Desantes, J.M., Salvador, F.J., Carreres, M., Jaramillo, D., "Experimental Characterization of the Thermodynamic Properties of Diesel Fuels Over a Wide Range of Pressures and Temperatures", SAE Int. J. Fuels Lubr. 8(1):2015, doi:10.4271/2015-01-0951.

Page 5 of 12 
temperatures due to their reduced viscosities.

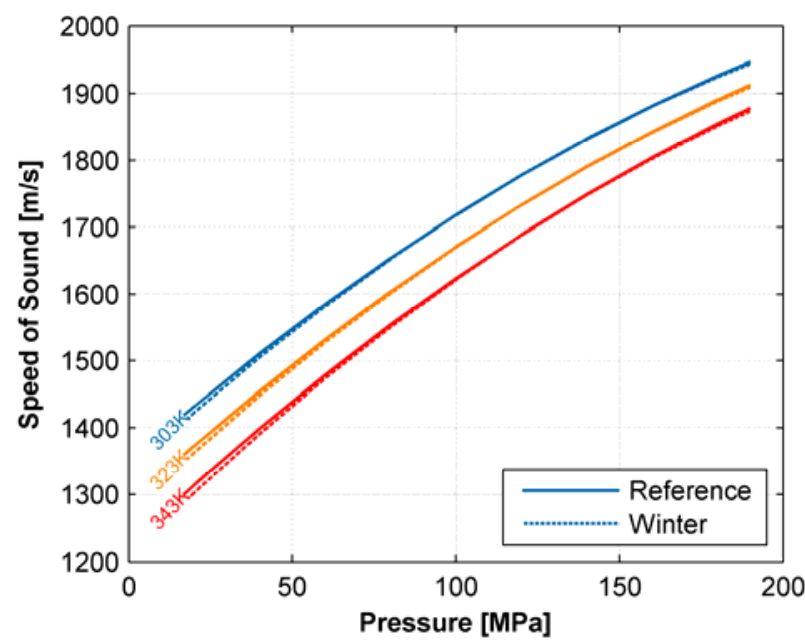

Figure 8. Speed of sound isothermal curves for the reference and winter fuels.

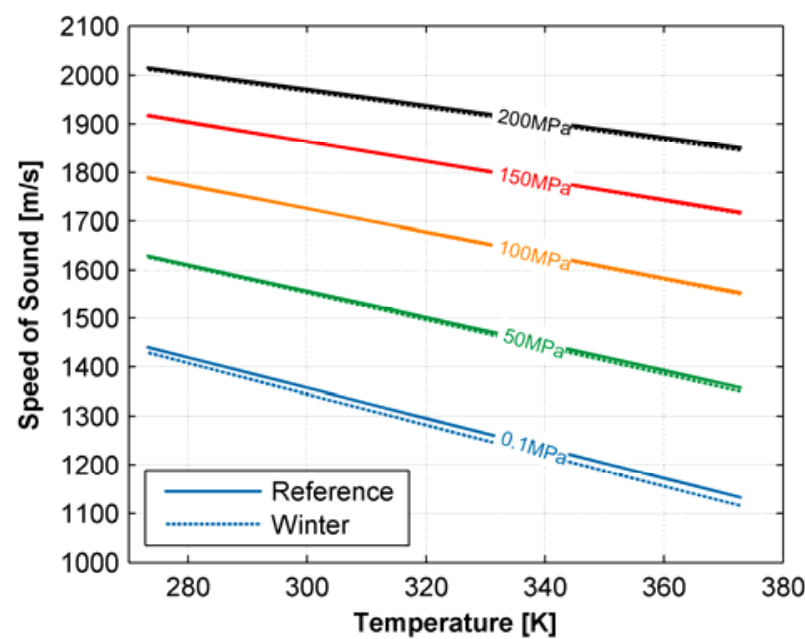

Figure 9. Speed of sound isobaric curves for the reference and winter fuels.

\section{Density determination}

As treated in the Experimental Work section and according to Eq. (7), density measurements need to be performed at different temperatures for a reference pressure, which has been taken as the atmospheric one. It is known that the behavior of the density with respect to the temperature for atmospheric pressure is linear. In order to have a practical expression to be introduced in Eq. (7), data have been fitted to a linear function:

$\rho\left(p_{0}, T\right)=B_{1}+B_{2} T$

The coefficients obtained for each fuel are represented in Table 4, together with the corresponding $\mathrm{R}^{2}$ values. $\mathrm{n}$-Heptane data was not obtained due to its availability in the literature [21]. Thus, the validity of the density results will be confirmed later at the complete range of Desantes, J.M., Salvador, F.J., Carreres, M., Jaramillo, D., "Experimental Characterization of the Thermodynamic Properties of Diesel Fuels Over a Wide Range of Pressures and Temperatures", SAE Int. J. Fuels Lubr. 8(1):2015, doi:10.4271/2015-01-0951. temperatures and pressures. The results of the measurements, performed with a hydrometer, together with the corresponding values obtained through the correlation of Eq. (11) are shown in Figure 10 for both the reference and the winter fuels. It can be observed that the trend of the density with the temperature for both fuels is identical (as can be confirmed by the coefficients $B_{2}$ of Table 3), and the only difference between the fuels is at the reference temperature and pressure (about $3 \mathrm{~kg} / \mathrm{m}^{3}$ ). This fact confirms the evidence stated previously about both fuels trying to present the same fuel properties regardless the operating conditions.

Table 4. Eq. (11) correlation coefficients for the different fuels, together with the $\mathrm{R}^{2}$ values.

\begin{tabular}{|l|l|l|l|}
\hline Fuel & $\mathrm{B}_{1}$ & $\mathrm{~B}_{2}$ & $\mathrm{R}^{2}$ \\
\hline Reference & 1128.1477 & -1.0179 & 0.9993 \\
\hline Winter & 1125.6785 & -1.0194 & 0.9959 \\
\hline
\end{tabular}

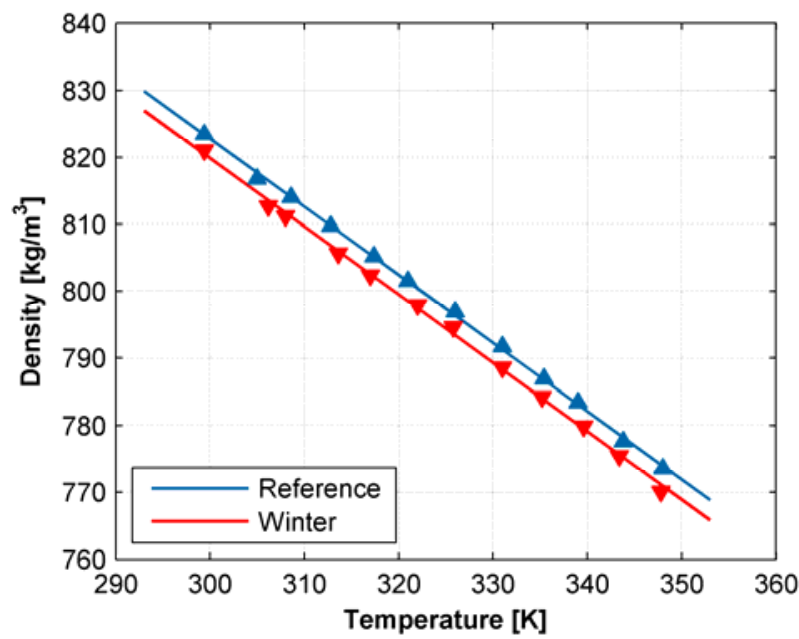

Figure 10. Density results against the temperature for the different fuels tested at atmospheric pressure. Experimental results are shown as symbols, whereas the corresponding regressions are plotted as continuous lines.

The next step to determine the density at any operating condition is to solve the second term of the right side of Eq. (7). Thus, it is needed to express the speed of sound as a function of pressure for each isothermal line measured. A polynomial expression has been chosen:

$\mathrm{a}(p)=C_{1}+C_{2} p+C_{3} p^{2}+C_{4} p^{3}$

The coefficients of Eq. (12) for each of the isothermal curves tested for n-Heptane are shown in Table 5. The values for the reference and winter fuels have been omitted for illustrative purposes.

Table 5. Eq. (12) correlation coefficients for the different isothermal curves tested experimentally for $n$-Heptane, together with the $\mathrm{R}^{2}$ values.

\begin{tabular}{|l|l|l|l|l|l|}
\hline Temperature $[\mathrm{K}]$ & $\mathrm{C}_{1}$ & $\mathrm{C}_{2}$ & $\mathrm{C}_{3}$ & $\mathrm{C}_{4}$ & $\mathrm{R}^{2}$ \\
\hline 303 & 1143.87 & 5.9723 & -0.004478 & $-5.775 \cdot 10^{-5}$ & 0.9999 \\
\hline 323 & 1048.95 & 7.2025 & -0.02069 & $1.230 \cdot 10^{-5}$ & 0.9999 \\
\hline
\end{tabular}

Page 6 of 12 


\begin{tabular}{|l|l|l|l|l|l|}
\hline 343 & 871.02 & 14.975 & -0.1781 & $1.0185 \cdot 10^{-}$ & 0.9987 \\
\hline
\end{tabular}

The high values of $\mathrm{R}^{2}$ show that this correlation is suitable to be substituted in Eq. (7) since it will not introduce a considerable error in the calculations.

Finally, considering its small influence in the result (its contribution to the total density represents around 1 to $2 \%$ ), the last term of Eq. (7) will be approximated considering that $\alpha$ and $C_{p}$ do not depend on the pressure for diesel fuels. As an example to support this fact, [22] shows that $C_{p}$ is hardly affected by pressure for the ISO4113, which is a test fluid with thermo physical properties similar to those of diesel fuels. Thus, Eq. (7) results in:

$$
\rho(p, T)=B_{1}+B_{2} T+\int_{p_{0}}^{p} \frac{d p}{\left(C_{1}+C_{2} p+C_{3} p^{2}+C_{4} p^{3}\right)^{2}}+T \frac{\alpha^{2}}{C_{p}}\left(p-p_{0}\right)
$$

where the coefficients $C_{1}, C_{2}, C_{3}$ and $C_{4}$ will be computed for the corresponding isothermal line of interest, whereas $C_{p}$ is considered to take a constant value of $2.25 \mathrm{~J} / \mathrm{K} \cdot \mathrm{g}$, representative of n-Dodecane at reference conditions [23]. Considering that $C_{p}$ for diesel fuels takes values from 1.89 to $2.37 \mathrm{~J} / \mathrm{K} \cdot \mathrm{g}$ on the studied range of temperatures and pressures $[21,22]$ and the small contribution of the third term of (13) on the total density, the estimated maximum error of this assumption is of $0.32 \%$. On the other hand, $\alpha$ is computed from the density measurements at atmospheric pressure as:

$\alpha=\frac{1}{V}\left(\frac{\partial V}{\partial T}\right)_{p}=-\frac{1}{\rho}\left(\frac{\partial \rho}{\partial T}\right)_{p}$

In an analogous way to the analysis for the speed of sound that has already been reported, Figures 11 and 12 show the comparison of the n-Heptane experimental results with the data from [21] in order to check the validity of the methodology. In Figure 11, the evolution of the density with the pressure is shown for the three isothermal curves tested. Figure 12, in turn, shows the evolution of density with respect to the temperature for the isobaric curves. The comparisons show good agreement of the experimental data with the theoretical values, with a $0.5 \%$ maximum deviation, which highlights the validity of the methodology implemented to determine diesel fuel densities. The evolution of the density with the temperature and pressure is as expected from previous works $[2,5,13,14]$ : it increases when the pressure increases, and decreases when the temperature increases.

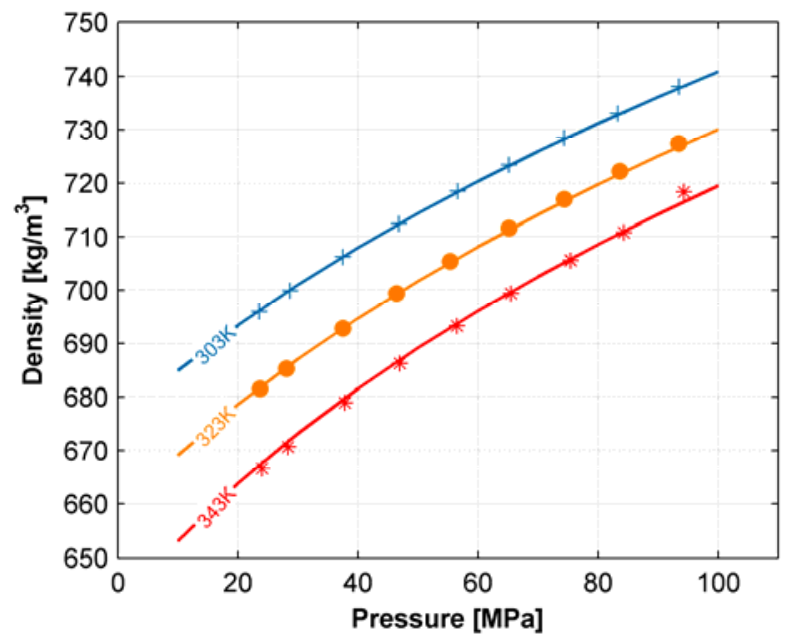

Figure 11. Density isothermal curves for n-Heptane compared to data from [21]. Experimental results are shown as symbols, whereas data from [21] is represented as continuous lines.

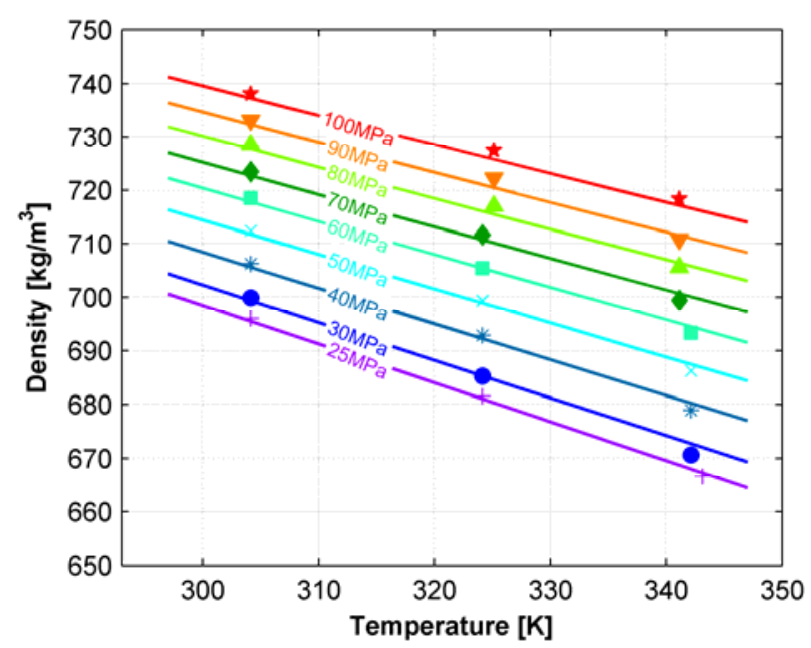

Figure 12. Density isobaric curves for n-Heptane compared to data from [21]. Experimental results are shown as symbols, whereas data from [21] is represented as continuous lines.

As it was performed for the speed of sound, in order to quantify the density trends with temperature and pressure, and dispose of suitable data for further reference in the future, the density results have been fitted to a polynomial expression:

$$
\begin{aligned}
\rho= & D_{1}+D_{2}\left(T-T_{0}\right)+D_{3}\left(T-T_{0}\right)^{2}+D_{4}\left(p-p_{0}\right)+ \\
& +D_{5}\left(p-p_{0}\right)^{2}+D_{6}\left(T-T_{0}\right)\left(p-p_{0}\right)
\end{aligned}
$$

Note that, in this case, the term gathering the dependency of the property with the squared temperature has been kept. As opposed to the speed of sound, there is a small non-linearity of density with respect to the temperature. The coefficients of this expression for each fuel are collected in Table 6, together with the statistical $\mathrm{R}^{2}$

Desantes, J.M., Salvador, F.J., Carreres, M., Jaramillo, D., "Experimental Characterization of the Thermodynamic Properties of Diesel Fuels Over a Wide Range of Pressures and Temperatures", SAE Int. J. Fuels Lubr. 8(1):2015, doi:10.4271/2015-01-0951.

Page 7 of 12 
values. These values are close to 1 , which highlights the ability of the polynomial correlation to reproduce the density trends.

Table 6. Eq. (15) correlation coefficients for the different fuels, together with the $\mathrm{R}^{2}$ values.

\begin{tabular}{|l|l|l|l|l|l|l|l|}
\hline Fuel & $\mathrm{D}_{1}$ & $\mathrm{D}_{2}$ & $\mathrm{D}_{3}$ & $\mathrm{D}_{4}$ & $\mathrm{D}_{5}$ & $\mathrm{D}_{6}$ & $\mathrm{R}^{2}$ \\
\hline n-Heptane & 680.65 & -0.638 & -0.00363 & 0.854 & -0.00227 & 0.0024 & 0.9998 \\
\hline Reference & 830.59 & -1.021 & 0.00153 & 0.566 & -0.00064 & 0.0013 & 0.9997 \\
\hline Winter & 826.54 & -1.021 & 0.00125 & 0.603 & -0.00083 & 0.0014 & 0.9995 \\
\hline
\end{tabular}

Figure 13 shows the experimental results for the reference fuel at the different isothermal lines that have been tested. Results are plotted together with the corresponding values obtained through the polynomial expression of Eq. (15). Again, there is good agreement among the experimental data and the values predicted by the correlation, as the high values of $\mathrm{R}^{2}$ suggested.

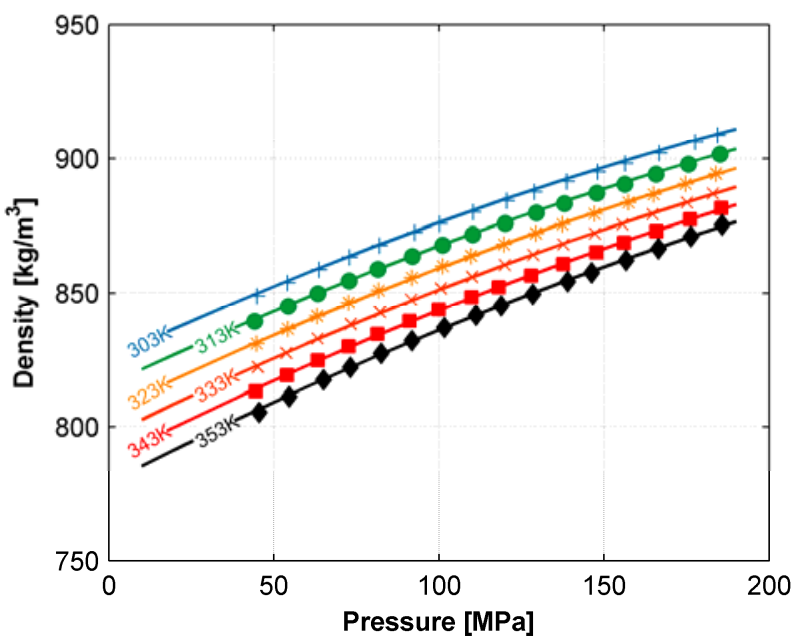

Figure 13. Speed of sound isothermal curves for the reference fuel. Experimental results are shown as symbols, whereas the values corresponding to the regression from Eq.(15) and Table 5 are represented as continuous lines.

Figures 14 and 15 show the results for the reference and winter fuels, considering only the values predicted by the respective correlations. Densities take very similar values for both fuels. Differences can be mostly attributed to the differences at atmospheric pressure, as it was seen in Figure 10. These differences only get higher at low pressures, due to the discrepancies in speed of sound values at these pressures (recall Figure 8). However, the density remains at similar values for both fuels, which highlights the possibility of interchange both fuels in a real diesel engine without substantially affecting the quantity of diesel mass injected in the cylinder.

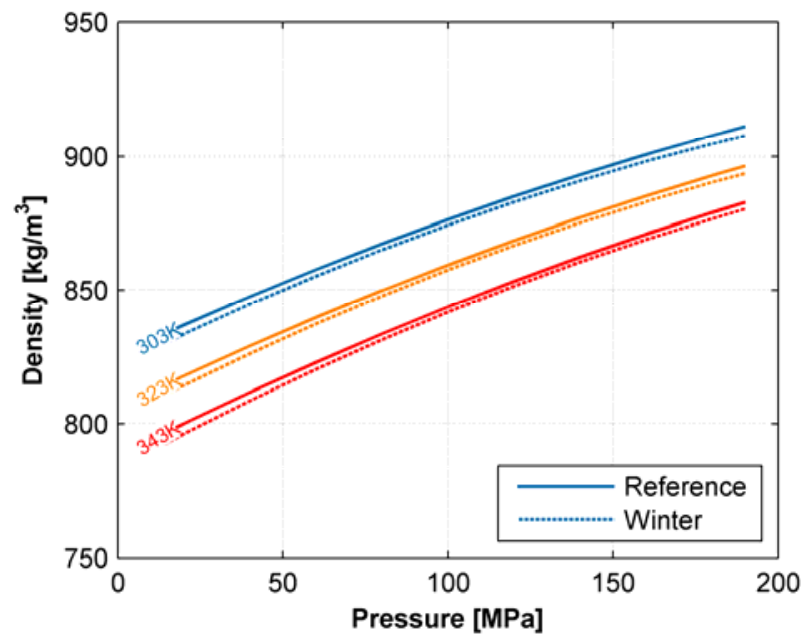

Figure 14. Density isothermal curves for the reference and winter fuels.

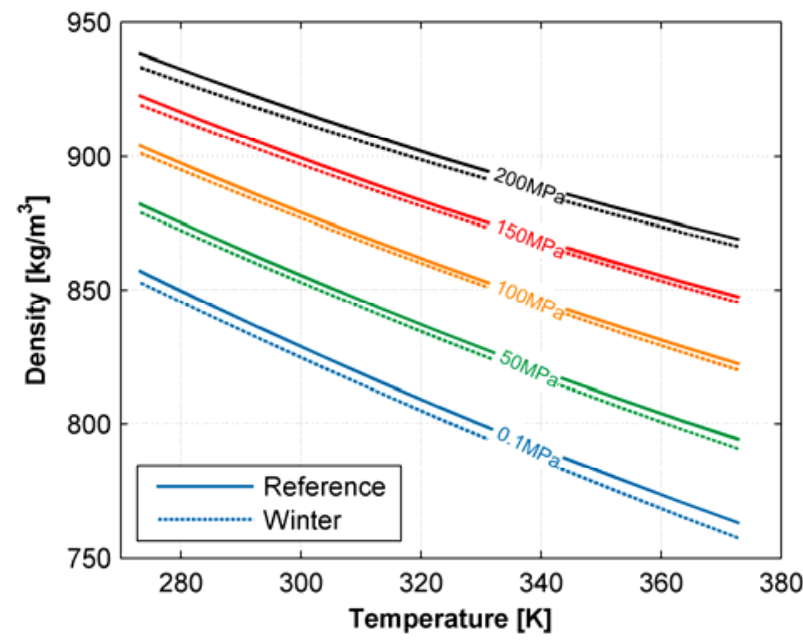

Figure 15. Density isobaric curves for the reference and winter fuels.

\section{Bulk modulus determination}

The isentropic bulk modulus can be directly obtained from both speed of sound and density measurements, recalling Eq. (5). This property is linear with the temperature, but a quadratic dependency with pressure has been considered. Thus, results have been fitted to a polynomial expression with the following terms:

$B_{S}=E_{1}+E_{2}\left(T-T_{0}\right)+E_{3}\left(p-p_{0}\right)+E_{4}\left(p-p_{0}\right)^{2}$

The coefficients of this expression for each fuel are collected in Table 7 , together with the statistical $\mathrm{R}^{2}$ values. The fact that these values remain high confirms the linear tendency of the bulk modulus with temperature and quadratic with pressure.

Desantes, J.M., Salvador, F.J., Carreres, M., Jaramillo, D., "Experimental Characterization of the Thermodynamic Properties of Diesel Fuels Over a Wide Range of Pressures and Temperatures", SAE Int. J. Fuels Lubr. 8(1):2015, doi:10.4271/2015-01-0951.

Page 8 of 12 
Table 7. Eq. (16) correlation coefficients for the different fuels, together with the $\mathrm{R}^{2}$ values.

\begin{tabular}{|l|l|l|l|l|l|}
\hline Fuel & $\mathrm{E}_{1}$ & $\mathrm{E}_{2}$ & $\mathrm{E}_{3}$ & $\mathrm{E}_{4}$ & $\mathrm{R}^{2}$ \\
\hline n-Heptane & $9.187 \cdot 10^{8}$ & $-7.615 \cdot 10^{6}$ & $1.199 \cdot 10^{7}$ & -8523.0 & 0.9992 \\
\hline Reference & $1.515 \cdot 10^{9}$ & $-8.741 \cdot 10^{6}$ & $1.169 \cdot 10^{7}$ & -6173.9 & 0.9998 \\
\hline Winter & $1.489 \cdot 10^{9}$ & $-8.766 \cdot 10^{6}$ & $1.199 \cdot 10^{7}$ & -7461.3 & 0.9998 \\
\hline
\end{tabular}

Figure 16 shows the experimental results for the reference fuel at the different isothermal lines that have been tested. Data are represented together with the values obtained through the polynomial expression of Eq. (16). Results for n-Heptane are omitted in this section since the validity of the methodology has already been proved for speed of sound and density, and the bulk modulus obtaining depends directly on both of them. It can be seen that the bulk modulus grows almost linearly with the pressure, although the authors confirmed a significant contribution of the quadratic term. Several authors have reported that the increase of the bulk modulus with pressure is related to an extra resistance to compression when the fuel is already compressed, since the molecules are closely packed together [13].

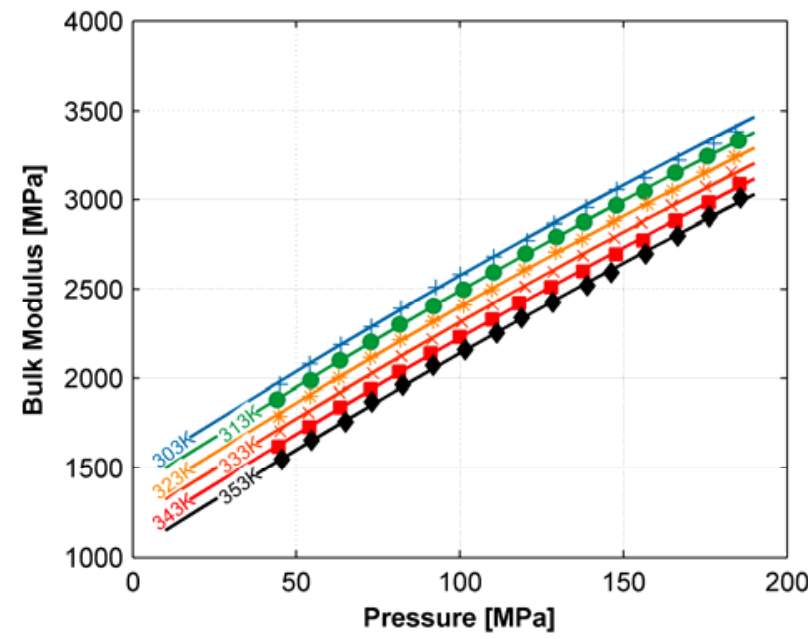

Figure 16. Isentropic bulk modulus isothermal curves for the reference fuel. Experimental results are shown as symbols, whereas the values corresponding to the regression from Eq.(16) and Table 6 are represented as continuous lines.

Figures 17 and 18 show the isentropic bulk modulus comparison for the reference and winter fuels, taking the data reported by the correlations of Eq. (16) for both fuels. The results for both fuels are very similar again, as it was expected since the bulk modulus depends directly on both the speed of sound and the density. Also, Figure 18 shows that the bulk modulus decreases with the temperature. With all, this property is mostly influenced by the pressure.

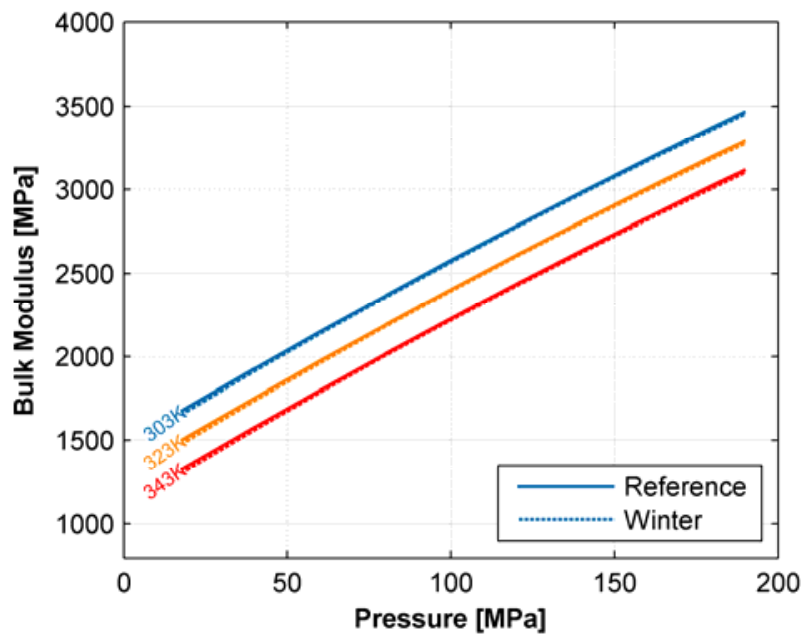

Figure 17. Isentropic bulk modulus isothermal curves for the reference and winter fuels.

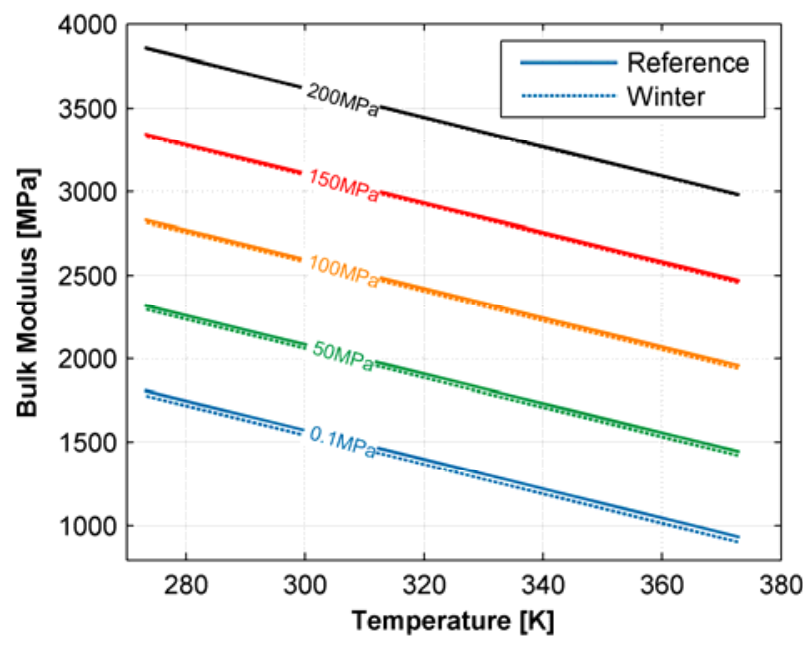

Figure 18. Isentropic bulk modulus isobaric curves for the reference and winter fuels.

\section{Conclusions}

A methodology to experimentally determine the evolution of some of the thermodynamic properties of diesel fuels that affect the performance of diesel engines with respect to the temperature and pressure has been implemented and assessed. Specifically, these properties are the speed of sound, density and bulk modulus. They have been evaluated for a range of temperatures (303 K to $353 \mathrm{~K}$ ) and pressures (up to $200 \mathrm{MPa}$ ) relevant for diesel engine operation, thus making the study profitable for the engine community, either to reproduce the experiments to measure new fuels or to make use of the data here presented.

An experimental facility to measure the speed of sound with a common-rail system has been described. The facility has been

Desantes, J.M., Salvador, F.J., Carreres, M., Jaramillo, D., "Experimental Characterization of the Thermodynamic Properties of Diesel Fuels Over a Wide Range of Pressures and Temperatures", SAE Int. J. Fuels Lubr. 8(1):2015, doi:10.4271/2015-01-0951.

Page 9 of 12 
calibrated with n-Dodecane, an alkane of known properties, and its validity has been checked with n-Heptane measurements. Results were obtained for a reference fuel and its winter variation, in order to determine the dependence of their properties with temperature and pressure. It has been demonstrated that these two fuels present similar properties for all the range of temperatures and pressures relevant for diesel engine operation, which highlights the changeability among them in normal conditions of operation. The purpose of the winter fuel is to extend the range of operation of the engine, probably by reducing the viscosity at low temperatures. For the temperature range considered in this study, it has been seen that it could be possible to use it instead of the reference fuel without substantial changes in the mass injected to the cylinder or the waves propagation, which would affect the hydraulic operation of the diesel injectors. Further investigations would need to be made at lower temperatures, also considering the viscosity, in order to extend the validity of this affirmation to extremely cold conditions.

Polynomial correlations have been obtained for the three properties studied with the aim of making it possible for modelers to incorporate the variation of the properties with pressure and temperature to their simulations. The high values of the $\mathrm{R}^{2}$ statistical obtained for all the correlations make it possible to use them without losing accuracy. Moreover, polynomial correlations are easy to implement in any simulation code and consume less computation resources than other kinds of correlations.

\section{References}

1. Payri, R., Salvador, F.J., Gimeno, J., and De la Morena, J., "Influence of injector technology on injection and combustion development - part 2: combustion analysis”, Appl. Energy 88(4):1130-1139, 2011. doi:10.1016/j.apenergy.2010.10.004.

2. Rodríguez-Anton, L.M., Casanova-Kindelan, J., and Tardajos, G. "High pressure physical properties of fluids used in diesel injection systems”, SAE Technical Paper 2000-01-2046, 2000, doi:10.4271/2000-01-2046.

3. Boehman, A.L., Morris, D., and Szybist, J., "The impact of bulk modulus of diesel fuels on fuel injection timing”, Energ. Fuel. 18(6):1877-1882, 2004, doi:10.1021/ef049880j.

4. Boudy, F., and Seers, P. "Impact of physical properties of biodiesel on the injection process in a common-rail direct injection system”, Energ. Convers. Manage. 50(12):2905-2912, 2009, doi:10.1016/j.enconman.2009.07.005.

5. Ndiaye, E.H., Bazile, J.P., Nasri, D., Boned, C., et al., "High pressure thermophysical characterization of fuel used for testing and calibrating diesel injection systems”, Fuel 98:288-294, 2012, doi:10.1016/j.fuel.2012.04.005.

6. Siebers, D.L., "Liquid-phase fuel penetration in diesel sprays", SAE Technical Paper 980809, 1998, doi:10.4271/980809.

7. Payri, R., García, J.M., Salvador, F.J., and Gimeno, J., "Using spray momentum flux measurements to understand the influence of diésel nozzle geometry on spray characteristics”, Fuel 84(5):551-561, 2005, doi:10.1016/j.fuel.2004.10.009.

8. Dernotte, J., Hespel, C., Foucher, F., Houillé, S, et al., "Influence of physical fuel properties on the injection rate in a Diesel injector”, Fuel 96:153-160, 2012, doi:10.1016/j.fuel.2011.11.073.

9. Salvador, F.J., Marti-Aldaravi, P., Carreres, M., and Jaramillo, D., "An Investigation on the Dynamic Behaviour at Different Temperatures of a Solenoid Operated Common-Rail Ballistic
Injector by means of a One-Dimensional Model”, SAE Technical Paper 2014-01-1089, 2014, doi:10.4271/2014-011089.

10. Tat, M.E., Van Gerpen, J.J., Soylu, S., Canakci, M., et al., “The speed of sound and isentropic bulk modulus of biodiesel at 21 degrees from atmospheric pressure to $35 \mathrm{MPa}, \mathrm{J}$. Am. Oil Chem. Soc. 77:285-289, 2000.

11. Bosch, W., "The Fuel Rate Indicator: A New Measuring Instrument For Display of the Characteristics of Individual Injection”, SAE Technical Paper 660749, 1966, doi:10.4271/660749.

12. Payri, F., Salvador, F.J,,Gimeno, J., and Bracho, G., "A new methodology for correcting the signal cumulative phenomenon on injection rate measurements”, Exp. Tech. 32(1):46-49, 2008, doi:10.1111/j.1747-1567.2007.00188.x.

13. Daridon, J.L., Lagrabette, A., and Lagourette, B., "Speed of sound, density and compressibilities of heavy synthetic cuts from ultrasonic measurements under pressure", J. Chem. Thermodyn. 30(5):607-623, 1998, doi:10.1006/jcht.1997.0330.

14. Dávila, M.J., and Trusler, J.P., "Thermodynamic properties of mixtures of N-methyl-2-pyrrolidinone and methanol at temperatures between $298.15 \mathrm{~K}$ and $343.15 \mathrm{~K}$ and pressures up to $60 \mathrm{MPa}$ ", J. Chem. Thermodyn. 41(1):35-45, 2009, doi:10.1016/j.jct.2008.08.003.

15. Freitas, S.V., Segovia, J.J., Martín, M.C, Zambrano, J., et al., "Measurement and prediction of high-pressure viscosities of biodiesel fuels”, Fuel 122:223-228, 2014, doi:10.1016/j.fuel.2014.01.031.

16. Desantes, J., Payri, R., Gimeno, J., and Marti-Aldaravi, P., "Simulation of the First Millimiters of the Diesel Spray by an Eulerian Spray Atomization Model Applied on ECN Spray A Injector", SAE Technical Paper 2014-01-1418, 2014, doi:10.4271/2014-01-1418.

17. Salvador, F.J., Gimeno, J., Pastor, J.M., and Marti-Aldaravi, P., "Effect of turbulence model and inlet boundary condition on the Diesel spray behavior simulated by an Eulerian Spray Atomization (ESA) model", Int. J. Multiphas. Flow 65:108-116, 2014, doi:10.1016/j.ijmultiphaseflow2014.06.003.

18. Shi, J., Guerrassi, N., Dober, G., Karimi, K., et al., "Complex physics modelling of diesel injector nozzle flow and spray supported by new experiments", presented at THIESEL 2014, Valencia (Spain), September 9-12, 2014.

19. Hayward, A.T., "How to measure the isothermal compressibility of liquids accurately", J. Phys. D: Appl. Phys. 4:938-950, 1971, doi:10.1088/0022-3727/4/7/308.

20. Ball, S.J., and Trusler, J.P., "Speed of sound of n-Hexane and nHexadecane at Temperatures Between 298 and $373 \mathrm{~K}$ and Pressures up to $100 \mathrm{MPa}$, Int. J. Thermophys. 22(2):427-443, 2001, doi:10.1023/A:1010770730612.

21. Bell, I.H., Wronski, J., Quoilin, S., and Lemort, V., "Pure and Pseudo-pure Fluid Thermophysical Property Evaluation and the Open-Source Thermophysical Property Library CoolProp”, Ind. Eng. Chem. Res. 53(6):2498-2508, 2014, doi:10.1021/ie4033999.

22. Chorazewski, M., Dergal, F., Sawaya, T., Mokbel, I., et al., "Thermophysical properties of Normafluid (ISO 4113) over wide pressure and temperature ranges", Fuel 105:440-450, 2013 doi:10.1016/j.fuel.2012.05.059.

23. Khasanshin, T.S., Shchamialiou, A.P., and Poddubskij, O.G., "Thermodynamic Properties of Heavy n-Alkanes in the Liquid State: n-Dodecane", Int. J. Thermophys. 24(5):1277-1289, 2003, doi:10.1023/A:1026199017598.

Desantes, J.M., Salvador, F.J., Carreres, M., Jaramillo, D., "Experimental Characterization of the Thermodynamic Properties of Diesel Fuels Over a Wide Range of Pressures and Temperatures", SAE Int. J. Fuels Lubr. 8(1):2015, doi:10.4271/2015-01-0951.

Page 10 of 12 


\section{Contact Information}

Mr. Marcos Carreres, marcarta@mot.upv.es

CMT-Motores Térmicos, UniversitatPolitècnica de València

Camino de Vera s/n, E-46022 Valencia (Spain)

Telephone: +34-963876555

Fax: +34-963877659

\section{Acknowledgments}

This work was partly sponsored by "Ministerio de Economía y Competitividad" (Spanish Ministry of Economy) in the frame of the project "Comprensión de la influencia de combustibles no convencionales en el proceso de inyección y combustión tipo diésel”, reference TRA2012-36932. The equipment used in this work has been partially supported by FEDER project funds "Dotación de infraestructuras científico técnicas para el Centro Integral de Mejora Energética y Medioambiental de Sistemas de Transporte (CiMeT), (FEDER-ICTS-2012-06)", in the frame of the operation program of unique scientific and technical infrastructure of the Ministry of Science and Innovation of Spain. This support is gratefully acknowledged by the authors.

The authors would also like to thank Jaime Gimeno, José Enrique del Rey, Borja Hurtado, Alberto Ponce and Guillermo Miró for their technical help in the experimental setup and their support during the measurements.

Desantes, J.M., Salvador, F.J., Carreres, M., Jaramillo, D., "Experimental Characterization of the Thermodynamic Properties of Diesel Fuels Over a Wide Range of Pressures and Temperatures", SAE Int. J. Fuels Lubr. 8(1):2015, doi:10.4271/2015-01-0951.

Page 11 of 12 


\section{Definitions/Abbreviations}

$\mathbf{A}_{\mathbf{i}}$

$\mathbf{B}_{\mathbf{i}}$

$\mathbf{B}_{\mathrm{S}}$

$\mathbf{B}_{\mathrm{T}}$

$\mathbf{C}_{\mathrm{i}}$

$\mathbf{C}_{\mathrm{p}}$

$\mathbf{C}_{\mathrm{v}}$

Di $_{\text {i }}$

$\mathbf{E}_{\mathrm{i}}$

IRDCI

$\mathbf{L}$

$\mathbf{L}_{0}$

S speed of sound coefficients for the polynomial

correlation

density coefficients for the linear correlation with temperature at atmospheric pressure

isentropic bulk modulus

isothermal bulk modulus

speed of sound coefficients for the correlation with pressure for a given isothermal curve

isobaric heat capacity

isochoric heat capacity

density coefficients for the polynomial correlation

isentropic bulk modulus coefficients for the polynomial correlation

Injection Rate Discharge Curve Indicator

pipe length

pipe calibrated length at a reference temperature and pressure

entropy p

$\mathbf{p}_{0}$

$\mathbf{t}$

$\boldsymbol{\alpha}$

$\boldsymbol{\alpha}_{\mathrm{t}}$

$\boldsymbol{\beta}_{\mathrm{t}}$

$\rho$

$\Delta \mathbf{L}$

$\Delta \mathbf{t}$ temperature

reference temperature

speed of sound

pressure

reference pressure

time

isobaric coefficient of thermal expansion

coefficient of thermal expansion of a pipe

coefficient of compressibility of a pipe

density

change in pipe length due to temperature and pressure variations

travel time of a pressure wave

Desantes, J.M., Salvador, F.J., Carreres, M., Jaramillo, D., "Experimental Characterization of the Thermodynamic Properties of Diesel Fuels Over a Wide Range of Pressures and Temperatures", SAE Int. J. Fuels Lubr. 8(1):2015, doi:10.4271/2015-01-0951.

Page 12 of 12 